\title{
Fabrication of 3D Thin Films by Spray Pyrolysis Method from Metal Phthalocyanines
}

\author{
Antonio Alanis ${ }^{1}$, Oxana Kharissova ${ }^{2}$, Servando Aguire $^{3}$, Romeo Selvas ${ }^{4}$, \\ Carlos Luna ${ }^{5}$, Idalia Gomez ${ }^{6}$, Jiechao Jiang ${ }^{7}$ \\ ${ }^{1,2,4,5}$ Department of Fisico-Mathematical Sciences, Universidad Autónoma de Nuevo León, Ave. Universidad s/n, Ciudad \\ Universitaria, San Nicolas de los Garza, Nuevo Leon,C.P. 66455, México. \\ ${ }^{3}$ CIMAV, Alianza Norte 202, Parque de Investigación e Innovación Tecnológica, Apodaca, Nuevo Leon, C.P. 66628, \\ Mexico. \\ ${ }^{6}$ Department of Chemical Sciences, Universidad Autónoma de Nuevo León, Ave. Universidad s/n, ciudad Universitaria, San \\ Nicolas de los Garza, Nuevo Leon, C.P. 66455, México \\ ${ }^{7}$ Materials Science and Engineering Department, University of Texas at Arlington, Arlington, TX 76019, USA.
}

\begin{abstract}
Carbon 3D structures were obtained by spray pyrolysis using toluene solution containing suspended nickel or magnesium phthalocyanines as precursors of metallic particles serving as catalysts for carbon phase formation. The process was conducted in a range of temperatures in a quartz tube in inert atmosphere on borosilicate glass supports where the nanometric layers of nanoparticles were deposited. The samples were analyzed by Scanning Electron Microscopy (SEM), Transmission Electron Microscopy (TEM), Infrared Spectroscopy Fourier Transform (FTIR) and Raman spectroscopy; their condusctivity was measured via Kelvin technique. The properties of formed nanolayers were analyzed according to metal nature in the phthalocyanine, temperature, carrier gas speed, and other process parameters. Possible MEMS applications of thus fabricated nanolayers are discussed.
\end{abstract}

Keywords—carbon nanotubes,phthalocyanines, Raman, spray pyrolysis, TEM.

\section{INTRODUCTION}

One of the emerging research areas aimed at improving the physicochemical properties of metallophthalocyanines is "nanostructuring". The spectrum of nanomaterials used in sensors is wide; the analysis of recent publications has made possible to identify various nanomaterials that have found applications as chemical sensors [1-9]. These include the following groups of nanomaterials: 1) nanoparticles, nanoclusters, nanocrystals and quantum dots, used mainly in optical, including biochemical immunosensors, less often in electrochemical sensors; 2) nanotubes, nanorods, nanowires, nanowires, used primarily in electrical (field effect transistor) and electrochemical sensors, less often in optical (biochemical) and piezosensors; 3) sensors based on the use of nanoscale organized film structures (Langmuir-Blodgett films and selfassembled mono- and multilayers), used mainly in optical, surface-acoustic and piezo-quartz (volume-acoustic) sensors. All kinds of nanoscale particles can be embedded in various organic or inorganic matrices (monolayers or films). Nanosensors based on such composite materials are used mainly for the detection of gases, although there are examples of their use in the analysis of liquid media. Carbon nanotubes have a number of unique properties that make their use promising in chemical sensors [10,11], and a wide range of electrical properties. Most of the tubes are semiconductors, but there are excellent conductors (in particular, better than silver) and even insulators. The conductivity of a nanotube depends on its geometric structure.

Phthalocyanine-based macrocycle systems (Pc) and their metal complexes (MPc) are promising candidates for classic applications, such as, for example, pigments [12], solar [13] and fuel cells [14], catalysts [15], semiconductors [16], gas sensors [17], corrosion inhibitors [18], electronic [19] and optical [20] devices, liquid crystalline materials [21], but also for design of nanomaterials [22,23]. Their surface chemistry [23] is a relatively young and growing field of research, caused by the tremendous versatility of these molecules and their metal complexes. Phthalocyanine complexes are formed with most metallic elements of the periodic system and, depending on the type of metal center, enormous variations in reactivity, electronic and magnetic properties and biological functionality can be found. Phthalocyanines share the conjugated $\pi$ extended system with porphyrins and, therefore, also share the ability of a strong absorption of light in the visible range. These macrocycles are thermally very stable and up to 500-800 K, so their thin films can be easily prepared by organic molecular beam epitaxy (OMBE) in vacuum [24]. Exploiting the intrinsic electronic, optic and spintronic properties of novel low-dimensional molecular materials, it is required that the electronic coupling with the supporting substrate is kept as low as possible. In this context, metal-supported ultra-thin insulating films on phthalocyanine basis have attracted great interest as 
substrates to study the intrinsic properties of organic and inorganic nanostructures. Obtaining matrices of uniformly oriented carbon nanotubes (CNTs) will significantly accelerate their use in electronics. Vertically oriented (with respect to the substrate) CNTs, used, for example, for field emission cathodes, are synthesized using various variants of the CVD method. It is much more difficult to lay the CNT horizontally, but this is what is required for most electronic devices. It is also known that several phthalocyanines are capable to form composites with carbon nanotubes (CNTs) [25] and graphene [26], as well as to destroy completely CNTs [27]. So, the main goal of this work was the in situ study of formation of thin films from the toluene-phthalocyanine system by spray pyrolysis, characterization and search of possible applications.

\section{EXPERIMENTAL PART}

Metal phthalocyanines MPc $(\mathrm{M}=\mathrm{Cu}, \mathrm{Ni}, \mathrm{Mg}, \mathrm{Zn}$; $97 \%$ purity) were purchased from Sigma-Aldrich Company and used as supplied. Toluene and ethanol were purchased in CTR (Monterrey, Mexico). Electron microscopy images were made in SEM and TEM equipment at the University of Texas at Arlington (TX, USA). IR-spectra were measured in ThermoScientific Nicolet equipment. Raman spectra (DXR Raman Microscope ThermoScientific) were collected using an excitation wavelength of $785 \mathrm{~nm}(1.58 \mathrm{eV})$.

Using MPc $(\mathrm{M}=\mathrm{Cu}, \mathrm{Ni}, \mathrm{Mg}, \mathrm{Zn})$ as precursors, carbon thin films were prepared by a spray-pyrolysis technique using the powders of MPc, dispersed in a mixture of toluene $\left(\mathrm{C}_{7} \mathrm{H}_{8}\right)$ and EtOH o mixture of toluene $\left(\mathrm{C}_{7} \mathrm{H}_{8}\right)$ and ferrocene. The $\mathrm{MPc}$ concentration in each sample was in the range of $0.05 \mathrm{wt} . \%, 0.5 \mathrm{wt} . \%$ and $1 . \mathrm{wt} . \%$. Solvent $(20 \mathrm{~mL}$, toluene and alcohol (1:1) and MPc o solvent $(20 \mathrm{~mL}$, toluene andferrocene $(0.05 \mathrm{wt} . \%)$ and MPc was injected to the system at a rate of $1 \mathrm{~mL} / \mathrm{min}$ in a preheater set to $200^{\circ} \mathrm{C}$ while nitrogen gas is supplied at a ratio of $1 \mathrm{~L} / \mathrm{min}$. After the preheater, the gas passed into a quartz tube which entered in an oven heated at $760^{\circ} \mathrm{C}$. This quartz tube contained borosilicate glass substrates, where thin nanofilms were deposited by 20 min. (Fig. 1).

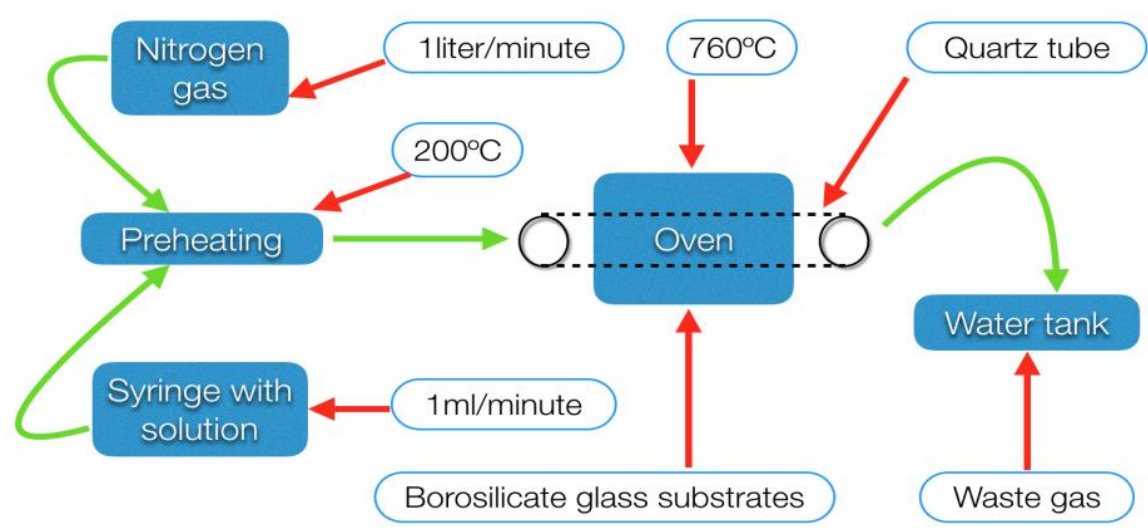

FIG. 1. The spray pyrolysis system.

The samples were characterized through scanning electron microscopy (SEM), transmission electron microscopy (TEM), by Raman and infrared spectroscopy (IR). The electrical measurements were carried out using the technique Kelvin-4 points. This method of measurement is the Kelvin, or 4-wire method. Special connecting clips called Kelvin clips are made to facilitate this kind of connection across a subject resistance (Fig. 2).
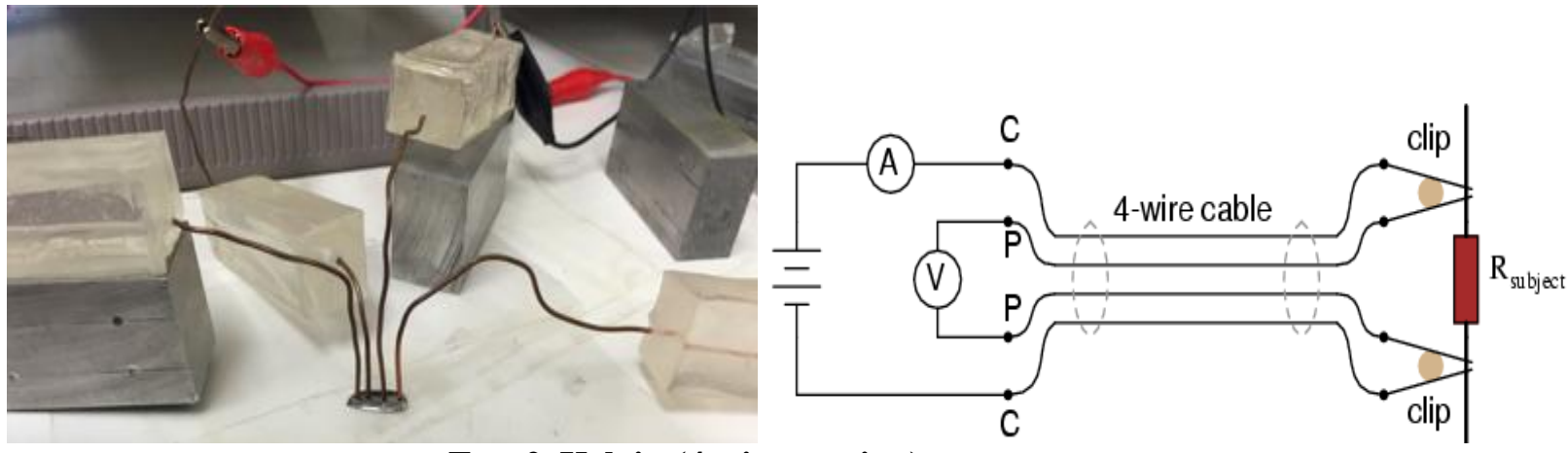

FIG. 2. Kelvin (4 wire sensing) measurements. 


\section{RESULTS AND DISCUSSION}

As a result of this work, the nanometric layers of carbon nanoparticles were deposited on quartz glass. These films were analyzed by scanning electron microscopy. First, the mixture of toluene $\left(\mathrm{C}_{7} \mathrm{H}_{8}\right)$ and $\mathrm{EtOH}$ with different concentration of MPc in each sample (0.05 wt.\%, 0.5 wt.\% and 1 wt.\%) (Fig. 3) was analyzed. As it is seen in SEM images, the morphology and thickness of the thin films varies (Table 1).

TABLE 1

DEPOSITION PARAMETERS AND RESULTING THIN FILM THICKNESS.

\begin{tabular}{|l|c|c|c|c|}
\hline Precursor & Concentration (wt.\%) & $\begin{array}{c}\text { Temperature of } \\
\text { deposition }\left({ }^{\circ} \mathbf{C}\right)\end{array}$ & $\begin{array}{c}\text { Time of deposition } \\
(\mathbf{m i n})\end{array}$ & Thickness (nm) \\
\hline MgPc & 1.0 & 760 & 20 & 1050 \\
\hline MgPc & 0.5 & 760 & 20 & 481 \\
\hline MgPc & 0.05 & 760 & 20 & 175 \\
\hline NiPc & 1.0 & 760 & 20 & 3458 \\
\hline NiPc & 0.5 & 760 & 20 & 1037 \\
\hline NiPc & 0.05 & 760 & 20 & 420 \\
\hline CuPc & 1.0 & 760 & 20 & 439 \\
\hline CuPc & 0.5 & 760 & 20 & 12 \\
\hline CuPc & 0.05 & 760 & 20 & 854 \\
\hline ZnPc & 1.0 & 760 & 20 & 857 \\
\hline ZnPc & 0.5 & 760 & 20 & 48 \\
\hline ZnPc & 0.05 & 760 & & 20 \\
\hline
\end{tabular}

The SEM and TEM data (Fig. 3) show that the MgPc blends allow obtaining the nanoparticles of 5-20 nm sizes (Fig. 3B) for $0.5 \mathrm{wt}$ \% concentrations. The morphology of deposited particles at concentrations of $0.5 \mathrm{wt}$. \% and $1.0 \mathrm{wt} . \%$ is shown in Fig. 3D. The morphology of the particles of larger sizes of $22-37 \mathrm{~nm}$ is present in the samples with $\mathrm{ZnPc}$ for concentrations 0.05 wt.\% (Fig. 3J) and increasing to $285-857 \mathrm{~nm}$ for concentrations of $1.0 \mathrm{wt}$ \% (Fig. 3M).According to the obtained results, different polymorphic phases of thin carbonaceous films were observed. Structural and morphological changes were found to be dependent on the nature of MPc.SEM data (Fig. 3) show that MgPc nanoparticles have sizes from 10 to $25 \mathrm{~nm}$ (Fig. 3B) and $20 \mathrm{~nm}$ (Fig. 3A), respectively. In the image profile of the sample of $0.5 \% \mathrm{NiPc}$ as precursor (Fig. 3G), it is shown how the nanoparticles are joined to the surface of borosilicate glass substrate.

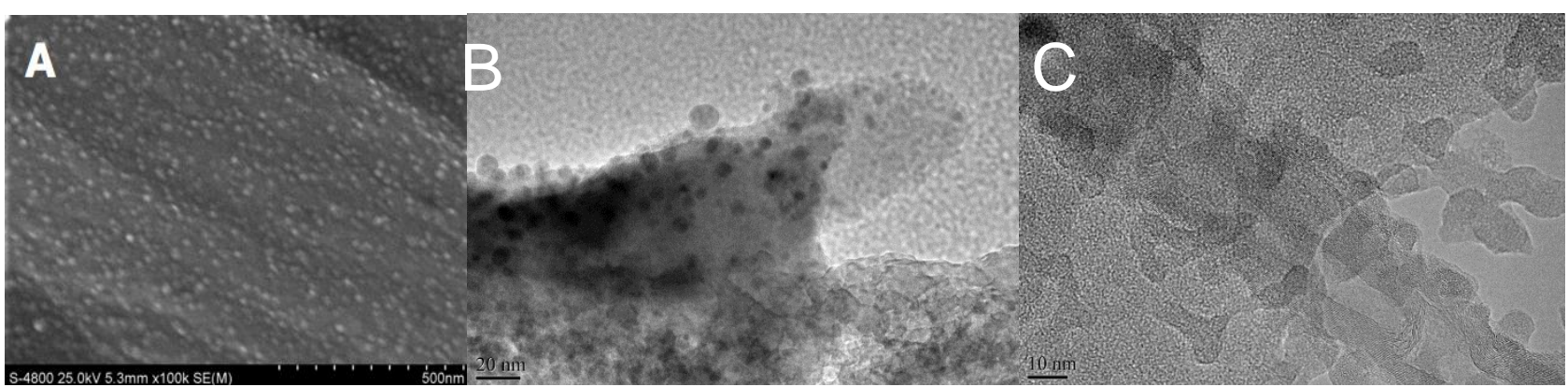




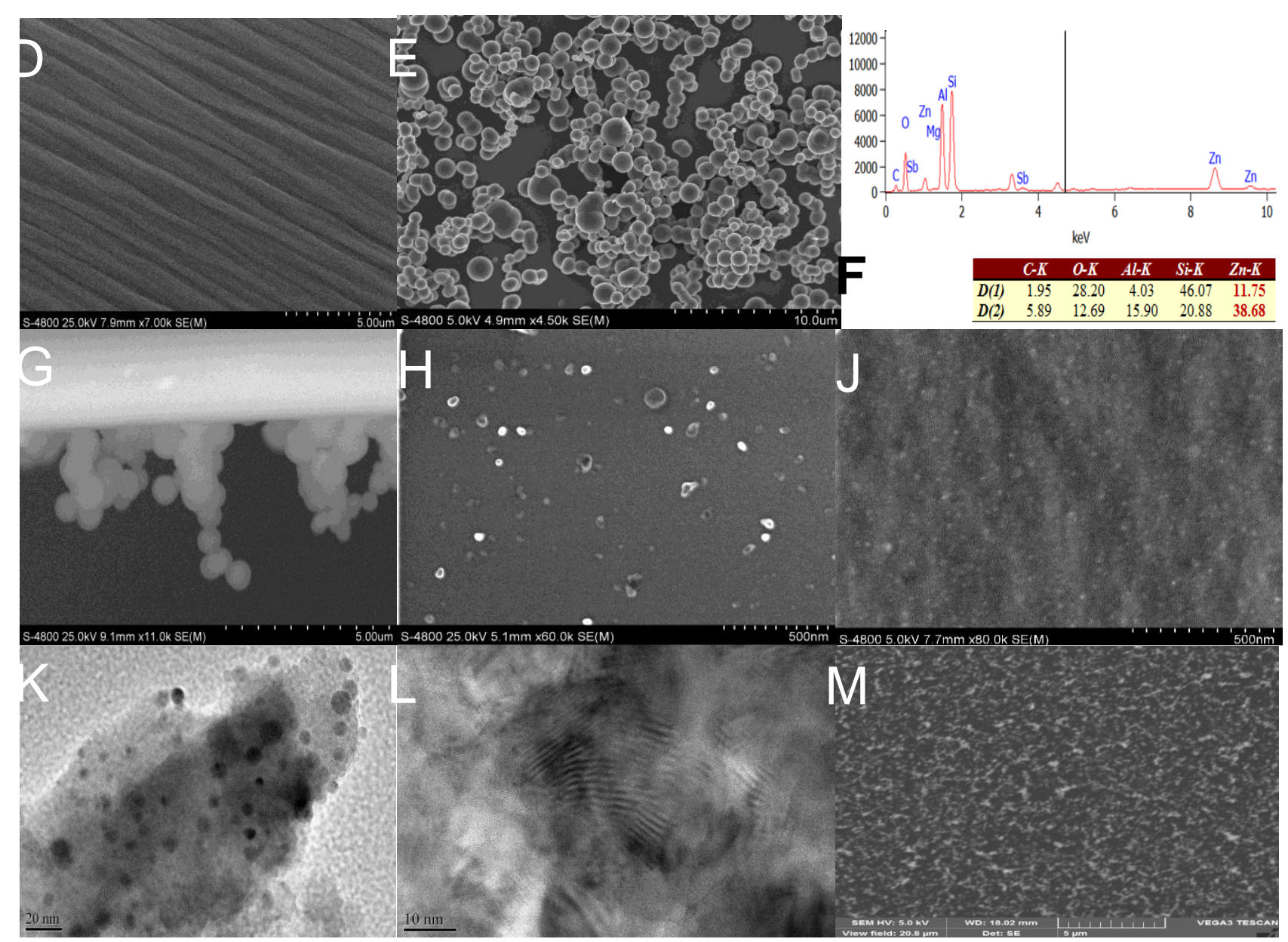

FIG. 3. Images of samples prepared using the following metal phthalocyanine precursors: A) SEM of MgPc 0.5 wt. \% ; B) TEM of MgPc 0.5 wt.\% ; C) TEM of MgPc 1.0 wt.\%; D) SEM of MgPc 1.0 wt.\%; E) SEM of NiPc 1.0 wt. \% ; F) EDS of ZnPc 1.0 wt.\% ; G) SEM of NiPc 0.5 wt. \% ; H) SEM of NiPc 0.05 wt. \% ; J) SEM of ZnPc 0.05 wt.\%; K) TEM of ZnPc 0.5 wt.\%; L) TEM of NiPc 1.0 wt.\%; M) SEM of ZnPc 1.0 wt.\%.

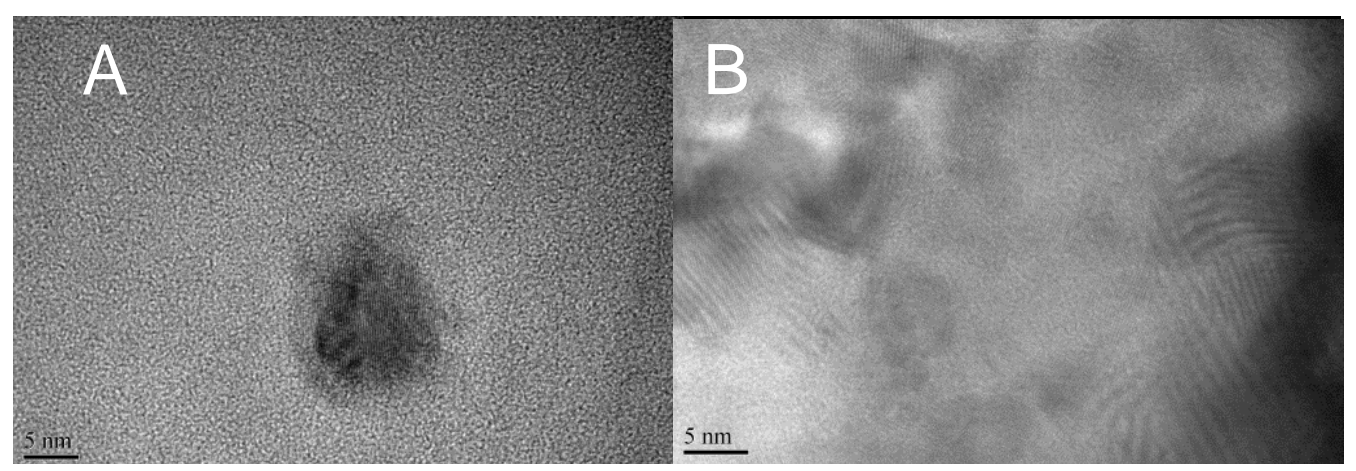

FIG. 4. TEM images of samples prepared using the CuPc precursors: A) TEM of CuPc 0.5 wt.\%; B) TEM of CuPc 1.0 wt.\%.

They have a size of $10-12 \mathrm{~nm}$ of the sample of $0.05 \%$ NiPc as precursor (Fig. 3H). The diameter of nanoparticles in case of $\mathrm{CuPc}$ use as a precursor is $15 \mathrm{~nm}$ (Fig. 4A). The thickness of thin film of the sample was found to be in the range of $20 \div 1000$ $\mathrm{nm}$ in case of homogeneous deposition (samples NiPc, $\mathrm{CuPc}$ and $\mathrm{MgPc}$ ); however, in case of the sample Fig. 3E ( $\mathrm{ZnPc}$ as a precursor) the deposition was not homogeneous and the thickness varies up to $3400 \mathrm{~nm}$ (Table 1). The TEM data reveal (Fig. 3 y Fig. 4) that the mixture with NiPc and CuPc allows obtaining nanoparticles of sizes 5-10 nm (Fig. 4A and Fig. 3H) for concentrations of $0.05 \mathrm{wt} . \%, 0.5 \mathrm{wt} . \%$ and formation of carbon nanotubes of SWCNT with diameter of $1.25 \mathrm{~nm}$ (Fig. 3L y Fig. 4B) for concentrations of $1.0 \mathrm{wt} . \%$. 
The Raman spectra of the samples are shown in Fig. 5. The modes of radial respiration (RBM) at $140 \leq v \leq 350 \mathrm{~cm}^{-1}$ is characteristic for SWCNTs, they are clearly present in all samples. The tangential $\mathrm{G}$ band at $1600 \mathrm{~cm}^{-1}$, whose profile indicates the metallic or semiconductor character of the CNTs, and the bands D at $1332 \mathrm{~cm}^{-1}$ (disorder-induced) and G' at $2650 \mathrm{~cm}^{-1}$ (overtone D) are also observed. The band D is indicative of the presence of defects in the walls, so the ratio of intensities of the $D$ and $G$ bands can testify about the number of defects [28]. In the Raman spectrum of samples, in addition to the bands G, D and G', a group of very intense bands centered at $200 \mathrm{~cm}^{-1}$ was observed, which are characteristics of SWNTs $\left(140 \leq v \leq 350 \mathrm{~cm}^{-1}\right)$ corresponding to the characteristic respiratory mode in radial direction (radial breathing mode RBM) of SWCNTs and inverse linearly depends CNT diameter. Since the radial breathing mode frequency $\omega_{R B M}$ depends linearly on the reciprocal nanotube diameter $d_{t}$.
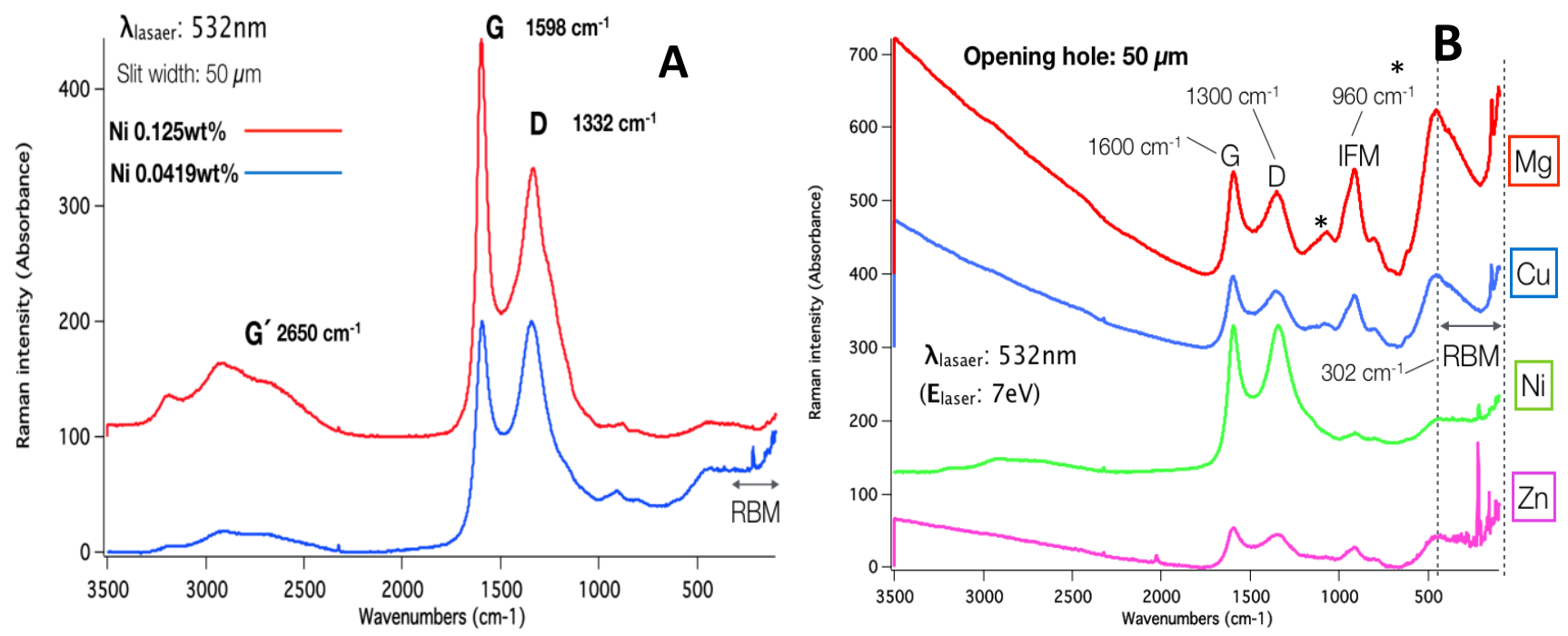

Fig. 5. Raman spectra of thin films: a) comparison of NiPc composites at different concentrations; b) comparison of samples obtained by pyrolysis using different MPc at $0.5 \mathrm{wt}$ \%. (RBM is Radial Breathing Mode $140 \leq v \leq 350 \mathrm{~cm}^{-1}$ ) and IFM (intermediate frequency modes IFM- $=750 \mathrm{~cm}^{-1}, \mathrm{IFM}^{+}=960 \mathrm{~cm}^{-1}$ ). The features marked with '*' at 248,521 and $962 \mathrm{~cm}^{-1}$ are from the $\mathrm{Si} / \mathrm{SiO}_{2}$ substrate and are used for calibration of the nanotube Raman spectrum [29]).

They can also correspond to other second-order vibrations as IFM (intermediate frequency modes) at $960 \mathrm{~cm}^{-1}$ (weaker bands). The first band $\mathrm{D}$ appears at $\sim 1300 \mathrm{~cm}^{-1}$, indicating the disorder of graphite. A strong increase of the band $\mathrm{G}$ is seen at $1600 \mathrm{~cm}^{-1}$ (vibration mode A1G). In case of NiPc use (Fig. 8a), a band at $\sim 2700 \mathrm{~cm}^{-1}$ confirms the stacking of graphene layers. The G-band is highly sensitive to strain effects in $\mathrm{sp}^{2}$ system, and thus can be used to probe modification on the flat surface of graphene.

Results of Kelvin ( 4 wire sensing) measurements. Voltage measurements against the current to a very small scale of the order of nano amperes in DC were made. The slope of the graph obtained in each of the samples being resistance is in the range of kilo ohms is achieved (Fig. 2). The summary of the readings taken with the technique Kelvin (4 wire sensing) is shown in Table 2. It was observed that there are three possible scenarios when depositing nanometer-thin layer of material on the substrate borosilicate glass as follows. 1) The nanometer-scale material is deposited on both sides of the substrate, 2) the material is deposited only on one side of the substrate, and 3) the nanometer material is deposited on any side of the substrate. This depends largely on the location of the substrate within the quartz tube, that is, if nothing is deposited in the terminals, if in the center, melts due to the high temperatures handled in the pyrolysis technique. It is recommended to place the substrates at a distance of $15 \mathrm{~cm}$ from the outside in the tube. Comparing the measurements of the samples from Table 2 we found that using only NiPc and $\mathrm{MgPc}$ in percentages $0.5 \mathrm{wt} . \%$ and $1.0 \mathrm{wt} . \%$, the resistance is relatively very high (from $25 \mathrm{k} \Omega$ to $75 \mathrm{k} \Omega$ ) having a very high current small but effective from $7.9 \mathrm{nA}$ to $20.6 \mathrm{nA}$ being sufficient to operate a MEMS. 
TABLE 2

SUMMARY OF THE MEASUREMENTS OF FOUR POINTS SAMPLES PYROLYSIS

\begin{tabular}{|c|c|c|c|c|c|c|}
\hline $\begin{array}{c}\text { Toluene } \\
\text { with }\end{array}$ & $\begin{array}{c}\text { Concentration } \\
\text { wt\% }\end{array}$ & $\begin{array}{c}\text { Initial } \\
\text { voltage } \\
\mu \text { volts }\end{array}$ & $\begin{array}{c}\text { Final } \\
\text { voltage } \\
\text { mvolts }\end{array}$ & $\begin{array}{c}\text { Initial } \\
\text { current } \mathbf{n A}\end{array}$ & $\begin{array}{c}\text { Final } \\
\text { current nA }\end{array}$ & Resistance $\mathbf{k} \boldsymbol{\Omega}$ \\
\hline \multirow{2}{*}{ MgPc } & 0.5 & 320 & 2.79 & 16.64 & 100 & 29.681 \\
\cline { 2 - 7 } & 1 & 226 & 2.25 & 20.60 & 100 & 25.477 \\
\hline \multirow{2}{*}{ NiPc } & 0.5 & 558 & 61.1 & 9.40 & 1000 & 61.156 \\
\cline { 2 - 7 } & 1 & 393 & 7.39 & 7.96 & 100 & 75.972 \\
\hline $\mathbf{Z n P c}$ & 0.5 & 428 & 2.47 & 14.23 & 100 & 17.356 \\
\hline $\mathbf{C u P c}$ & 0.5 & 341 & 7.01 & 21.45 & 1000 & 15.34 \\
\hline
\end{tabular}

The metal-phthalocyanines (MPc) is very sensitive and selective to different gases and solvents as an account of the central metal atoms of the molecule, which can easily be varied. The surface morphologies and the grain boundaries of organic thin films can influence the sensing property of OTFT sensors. The sensitivities of the MPcs ( $\mathrm{ZnPcs}, \mathrm{MgPc}, \mathrm{CuPc}, \mathrm{NiPc})$ to hydrogen peroxide may be determined as the slope $\left(\% \mathrm{ppm}^{-1}\right)$ of the sensor. The linear fits of responses versus concentration show modest non-ideal behavior in that the intercepts are non-zero; this is likely due to the influence of the water present in each dose, which acts as an offset. Sensitivities are presented in Table 3.The reaction of $\mathrm{NiPc}, \mathrm{CuPc}, \mathrm{ZnPc}$, and $\mathrm{H}_{2} \mathrm{Pc}$ with hydrogen peroxide can be portrayed as a radical reaction (1) or as a charge transfer process (2) following coordination:

$$
\begin{aligned}
& \mathrm{MPc}+\mathrm{HOOH} \rightarrow \mathrm{MPC}^{\bullet+}+\mathrm{OH}^{-}+{ }^{\circ} \mathrm{OH} \\
& \mathrm{MPc}+\mathrm{HOOH} \rightarrow\left[\mathrm{MPc}---\mathrm{HOOH} \leftarrow \mathrm{MPc}^{\delta+}---\mathrm{HOOH}^{\delta-}\right]
\end{aligned}
$$

\section{TABLE 3}

Sensitivities $\left(\% \mathrm{ppm}^{-1}\right)$ for MPcs $\left(\mathrm{M}=\mathrm{Mg}, \mathrm{Ni}, \mathrm{Cu}, \mathrm{Zn}, \mathrm{H}_{2}\right)$ to $25 \% \mathrm{H}_{2} \mathrm{O}_{2}(\mathrm{aq})$ and di-t-butyl peroxide vapors in the kinetic dosing regimen at $50^{\circ} \mathrm{C}$ and $8 \mathrm{~V}$.

\begin{tabular}{|c|c|c|}
\hline MPc & $\begin{array}{c}\text { Hydrogen peroxide sensitivities } \\
\left(\% \mathbf{~ p p m}^{-1}\right) \mathbf{~} \mathbf{1 0}^{-2}\end{array}$ & $\begin{array}{c}\text { Di-t-butyl peroxide sensitivities } \\
\left(\% \mathbf{~ p p m}^{-1}\right) \mathbf{~ 1 0}\end{array}$ \\
\hline $\mathbf{Z n P c}$ & $2.5 \pm 0.7$ & $0.4 \pm 0.2$ \\
\hline $\mathbf{C u P c}$ & $29.2 \pm 5.3$ & $3.5 \pm 1.3$ \\
\hline $\mathbf{N i P c}$ & $2.2 \pm 0.8$ & $0.3 \pm 0.1$ \\
\hline $\mathbf{M g P c}$ & $2.1 \pm 0.6$ & $0.4 \pm 0.2$ \\
\hline $\mathbf{H}_{2} \mathbf{P c}$ & $26.4 \pm 4.9$ & 0 \\
\hline
\end{tabular}

\section{CONCLUSIONS}

SWCNT monolayers having diameters of $1.45 \mathrm{~nm}$ were obtained by spray pyrolysis of toluene-ethanol dispersion of metal phthalocyanines as precursors of catalysts for carbon nanotube formation. Thin layers of nanomaterials were deposited on borosilicate glass and were found to conduct in nanoamper scale. The deposited material may be present on both sides of the substrate or on one side only. The nanoparticles were homogeneously distributed and have diameters of $20 \mathrm{~nm}$ and $750 \mathrm{~nm}$ for magnesium and nickel phthalocyanines used as precursors, respectively.

The G, D and G' characteristic bands of SWCNTs were confirmed by Raman spectroscopy, as well as other intense bands in the range of 140 to $350 \mathrm{~cm}^{-1}$ corresponding to RBM (radial breathing mode) and a less intensive band intermediate frequency modes (IFM) $750 \mathrm{~cm}^{-1}, 960 \mathrm{~cm}^{-1}$ corresponding to the IFM- and IFM+.

\section{ACKNOWLEDGEMENTS}

The authors gratefully acknowledge the helpful to the CONACYT-Mexico for Ph.D. scholarship for Antonio Alanis. 


\section{REFERENCES}

[1] Riu J., Maroto A., Rius F.X. Talanta, 2006, v. 69, p. 288-301.

[2] Shi J., Zhu Y., Zhang X., Baeyens W.R.G., Garcia-Campana A.M. Trends Anal. Chem., 2004, v. 23, 5, p. 351-360.

[3] Costa-Fernandez J.M., Pereiro R., Sanz-Medel A. Ibid., 2006, v. 25, 3, p. 207-218.

[4] Huang X.-J., Choi Y.-K. Sensors and Actuators B, 2007, v. 122, p. 659-671.

[5] He L., Toh C.-S. Anal. Chim. Acta, 2006, v. 556, p. 1-15.

[6] Jeronimo P.C.A., Araujo A.N., Montenegro M.C.B.S.M. Talanta, 2007, v. 72, p. 13-27.

[7] Tansil N.C., Gao Z. Nanotoday, 2006, v.1, № 1, p.28-37.

[8] Vaseashta A., Dimova-Malinovska D. Sci. Technol. Adv. Mater., 2006, v. 6, p. 312-318.

[9] James S.W., Tatam R.P. J. Opt. A: Pure Appl. Opt., 2006, v. 8, p. 430-444

[10] Merkoci A. Microchim. Acta, 2006, v. 152, p.157-164.

[11] Wildgoose G.G., Banks C.E., Levebtis H.C., Compton R.G. Ibid., 2006, v. 152, p. 187-214

[12] Sakamoto K., Okumura E., Materials 2009, 2, 1127-1179.

[13] Walter P.M.G., Rudine A.B., Wamser C.C. J. Porphyrins Phthalocyanines 2010, 14, p. 759-792.

[14] Burkitt R., Whiffen T.R., Hao Yu E., Applied Catalysis B: Environmental, 2016, v. 181, p. 279-288.

[15] Ma J., Liu Y., Zhang P., Wang J. Electrochemistry Communications 2008 v. 10(1) p. 100-102.

[16] Sorokin A.B. Chem. Rev., 2013, 113(10), p. 8152-8191

[17] Patois T., Sanchez J.B., Berger F., Fievet P., Segut O., Moutarlier V., Bouvet M., Lakard B., Talanta. 2013, 117, p.45-54

[18] Peng Zhao, Qiang Liang, Yan Li. Applied Surface Science, 2005, 252, p. 1596-1607.

[19] Raval H.N., Sutar D.S., Ramgopal Rao V. Organic Electronics, 2013, v. 14, 5, p 1281-1290

[20] Rodríguez Gómez A., Sánchez-Hernández C.M., Fleitman-Levin I., Arenas-Alatorre J., Alonso-Huitrón J.C., Sánchez Vergara M.E., Materials, 2014, 7, p.6585-6603.

[21] Iannuzzi M., Tran F., Widmer R., Diene T., Radican K., Ding Y., Hutter J., Gröning O. Physical Chemistry Chemical Physics. 2014, 16 (24), p.12374

[22] Nilson K., Ahlund J., Shariati M., Gothelid E., Palmgren P., Schiessling J., Berner S., Martensso N. and Puglia C. J. Phys. Chem. C, 2010, 114, p.12166.

[23] Das S., Magut P.K.S., Zhao L., Hasan F., Karki A.B., Jin R. and Warner I.M. RSC Adv., 2015, 5, p.30227-30233.

[24] Gottfried J.M. Surface Science Reports, 2015, v. 70, 3, p. 259-379.

[25] Wang Y., Chen H.-Z., Li H.-Y., Wang M. Materials Science and Engineering: B, Volume 117, Issue 3, 25 March 2005, Pages 296301.

[26] Mani V., Devasenathipathy R., Chen S.-M., Gu J.-A., Huang S.-T., Renewable Energy, 2015, v.74, p. 867-874.

[27] Kharissova O.V., Dias H.V.R., Kharisov B.I., Jiang J. RSC Advances, 2015, 5, p. 57764-57770.

[28] Dresselhaus M.S., Dresselhaus G., Jorio A., Souza Filho A.G., Saito R. Carbon, 2002, 40, 2043-2061

[29] Temple P.A., Hathaway C.E. Phys Rev B, 1973, 7, p.3685-3697. 